This item was submitted to Loughborough's Research Repository by the author.

Items in Figshare are protected by copyright, with all rights reserved, unless otherwise indicated.

\title{
Mechanical behaviours and mass transport properties of bone-mimicking scaffolds consisted of gyroid structures manufactured using selective laser melting
}

\section{PLEASE CITE THE PUBLISHED VERSION}

https://doi.org/10.1016/j.jmbbm.2019.01.023

\section{PUBLISHER}

(C) Elsevier

\section{VERSION}

AM (Accepted Manuscript)

\section{PUBLISHER STATEMENT}

This paper was accepted for publication in the journal Journal of the Mechanical Behavior of Biomedical Materials and the definitive published version is available at https://doi.org/10.1016/j.jmbbm.2019.01.023.

\section{LICENCE}

CC BY-NC-ND 4.0

\section{REPOSITORY RECORD}

Ma, Shuai, Qian Tang, Qixiang Feng, Jun Song, Xiaoxiao Han, and Fuyu Guo. 2019. "Mechanical Behaviours and Mass Transport Properties of Bone-mimicking Scaffolds Consisted of Gyroid Structures Manufactured Using Selective Laser Melting". figshare. https://hdl.handle.net/2134/37128. 


\section{Highlights}

- Gyroid scaffold has superior mechanical properties to mimic human bone;

- Gyroid scaffold has adjustable permeability properties to match human bone;

- SLM-produced gyroid scaffold has good consistency with its designing CAD model. 


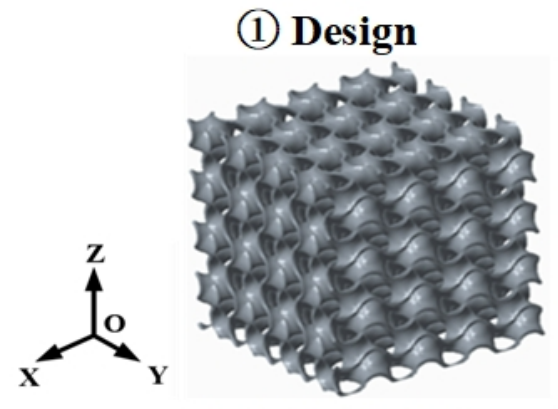

Gyroid structure

(2) Manufacture

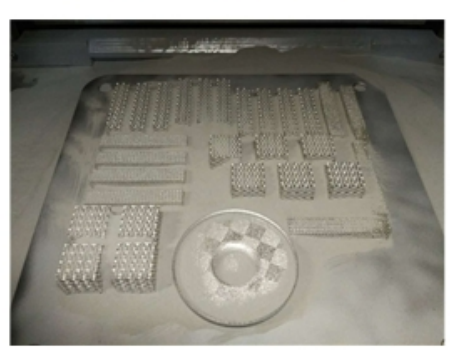

Selective laser melting

\section{(3) Experiments}
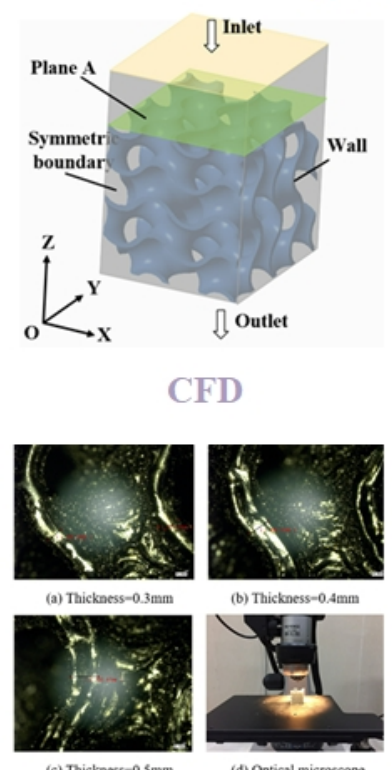
(d) Optical microscope

Optical microscopy analysis

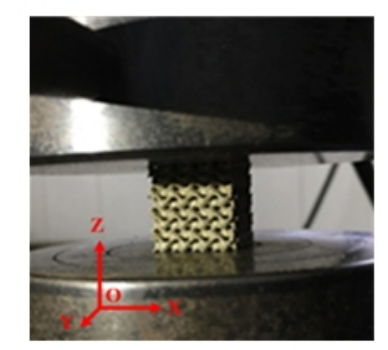

Compression test

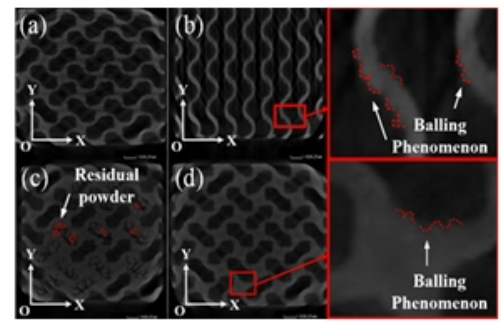

Micro-CT scanning

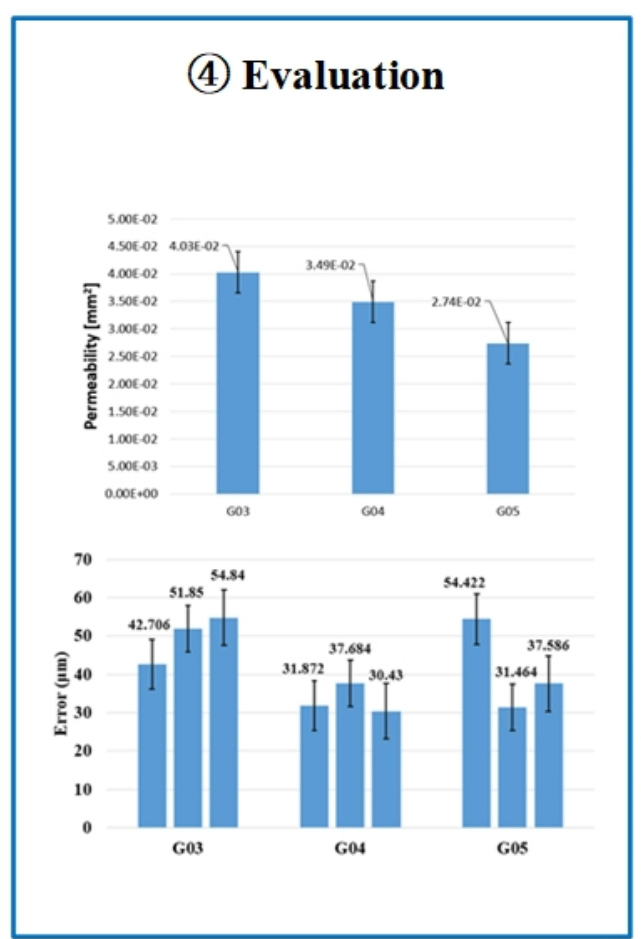




\title{
Mechanical Behaviours and Mass Transport Properties of Bone- Mimicking Scaffolds Consisted of Gyroid Structures Manufactured Using Selective Laser Melting
}

\author{
Shuai Ma ${ }^{1}$, Qian Tang ${ }^{1 *}$, Qixiang Feng ${ }^{1}$, Jun Song ${ }^{1}$, Xiaoxiao Han ${ }^{2}$, Fuyu Guo ${ }^{1}$ \\ 1-State Key Laboratory of Mechanical Transmissions, Chongqing University, Chongqing, \\ China \\ 2- Additive Manufacturing Research Group, Loughborough University, UK
}

\begin{abstract}
Bone scaffolds created in porous structures manufactured using selective laser melting (SLM) are widely used in tissue engineering, since the elastic moduli of the scaffolds are easily adjusted according to the moduli of the tissues, and the large surfaces the scaffolds provide are beneficial to cell growth. SLM-built gyroid structures composed of $316 \mathrm{~L}$ stainless steel have demonstrated superior properties such as good corrosion resistance, strong biocompatibility, self-supported performance, and excellent mechanical properties. In this study, gyroid structures of different volume fraction were modelled and manufactured using SLM; the mechanical properties of the structures were then investigated under quasi-static compression loads. The elastic moduli and yield stresses of the structures were calculated from stress-strain diagrams, which were developed by conducting quasi-static compression tests. In order to estimate the discrepancies between the designed and as-produced gyroid structures, optical microscopy and micro-CT scanner were used to observe the structures' micromorphology. Since good fluidness is conducive to the transport of nutrients, computational fluid dynamics (CFD) values were used to investigate the pressure and flow velocity of the channel of the three kinds of gyroid structures. The results show that the sizes of the as-produced structures were larger than their computer aided design (CAD) sizes, but the manufacturing errors are within a relatively stable range. The elastic moduli and yield stresses of the structures improved as their volume fractions increased. Gyroid structure can match the mechanical properties of human bone by changing the porosity of scaffold. The process of compression failure showed that $316 \mathrm{~L}$ gyroid structures manufactured using SLM demonstrated high degrees of toughness. The results obtained from CFD simulation showed that gyroid structures have good fluidity, which has an accelerated effect on the fluid in the middle of the channel, and it is suitable for transport nutrients. Therefore, we could predict the scaffold's
\end{abstract}


permeability by conducting CFD simulation to ensure an appropriate permeability before the scaffold being manufactured. SLM-built gyroid structures that composed of 316L stainless steel were suitable to be designed as bone scaffolds in terms of mechanical properties and mass-transport properties, and had significant promise.

Keywords SLM technique, tissue engineering, gyroid structure, bone scaffold, CFD

\section{Introduction}

Porous structures such as honeycomb [1], crystalline lattices [2], Voronoi foam [3], and gyroid lattices [4], all of which are manufactured using selective laser melting (SLM), have significant advantages: they are lightweight, they can reduce the consumption of materials, and they allow for mechanical property adjustment. These structures are widely used in aerospace engineering [5], product repair, tissue engineering [6], and as filling structures in addition to saving processing time and reducing powder consumption. SLM is an advanced process due to its efficiency in producing complex parts of many kinds of metal materials, including aluminium $[7,8]$, Invar [8], cobalt chrome alloy [9], titanium [10], stainless steel [11, 12], and pure gold [13]. Some metallic lattice structures can be manufactured using traditional processes such as casting [14-16], but the traditional approach to process parts with a complex structure is difficult, these parts are applied in specific work condition, such as under complex force condition that requires gradient porous structures, and parts that needs complex structure for conformal cooling. Cheng et al. compared the specific strength of stochastic foam structures and reticulated mesh structures under the some condition of identical specific stiffness, found that the regular mesh structures had higher specific strength [10]. Processing parameters such as scanning speed, layer thickness, point distance, and the shape of the porous structures affect the mechanical properties of the parts. The material the present study used is $316 \mathrm{~L}$ stainless steel $(316 \mathrm{~L})$, which is a widely used material in SLM. The elastic modulus of $316 \mathrm{~L}$ is around $206 \mathrm{GPa}$, the yield strength is around 267.2 MPa, and the density is $7.98 \mathrm{~g} / \mathrm{cm}^{3}$.

To explore the differences between designed and as-produced morphological properties, Bael et al. used micro-focus X-ray computed tomography (CT) imaging to analyse the errors between designed and as-produced morphological properties [17]. Along similar lines, McKown et al. investigated progressive collapse and associated 
failures by manufacturing a range of metallic lattice structures using the SLM rapid manufacturing technique [18]. Additionally, Feng et al. proposed an analytical modelling approach by conducting quasi-static analysis on Ti6A14V (Ti64) lattice structures; the approach was validated by conducting uniaxial compression tests on samples fabricated using SLM [19].

Gyroid structure is one kind of triply periodic minimal surfaces (TPMS), the TPMS have zero mean curvature and smooth surfaces, and it is considered to use in the biomedical field [20]. In terms of manufacturability, the gyroid structure has selfsupported feature that does not require the building of support structures, and this selfsupported features is suitable for being fabricated by SLM technology without additional support structure [21]. In terms of mechanical property, Olivares et al. indicated that gyroid structure has better interconnection and accessibility of fluid than hexagonal structure, which can provide good ability of cell seeding and transport of the nutrients [22]. Jung et al. used 3D graphene foams to investigate the mechanics of three kinds of TPMS structures, and indicated that gyroid structure has isotropic elasticity [23]. Qin et al. built gyroid structure to investigate the effect of defects of idealized atomic 3D graphene structure, and demonstrated that density and the connectivity between flakes are important factors, which can affect mechanical properties [24]. I. Maskery et al. investigated the failure modes in double gyroid structures made of AlSi10-Mg, and indicated that the gyroid structures were suitable for energy absorbing applications [4]. In terms of biocompatibility, TPMS can provide large surface area for cell adhesion due to the high surface to volume ratio. Gyroid architecture facilitates the permeation of fluid due to the open structure [25].

The surfaces of parts manufactured using SLM are rough, with a size larger than the designed value [21]. SLM is a feasible process for manufacturing complex structures that cannot be fabricated through traditional manufacturing methods [26], and it is a good way to control internal structures [27]. SLM provides a feasible method for bone scaffold manufacturing because the technique can be used to fabricate the bionic structure of bone trabeculae $[28,29]$. In order to better simulate the structure of bone trabeculae, the porous structure must be designed carefully by paying attention to porosity, pore size, and the shape of the structure [30]. The shape of the porous structure's units could influence permeability [31, 32], the structure's mechanical properties, and the type of cell differentiation.

The bone scaffold does have good mechanical properties, because the scaffold can 
sustain some of the pressure when it is implanted into the human body. Bobbert et al. investigated the quasi-static mechanical properties, fatigue resistance, and permeability of four different types of TPMS made of Ti-6Al-4V [33]. To research the mechanical behaviour differences between octahedral and gyroid unit cells, Speirs et al. designed three different unit cells of SLM nitinol scaffold, including octahedral, cellular gyroid, and sheet gyroid cells. The results showed that the gyroid structure has superior static mechanical properties compared to the octahedral structure under identical volume fractions [34].

The cell culture in vitro is considered as an effective experiment to investigate the biocompatibility of porous scaffolds. The permeability of scaffolds is an important factor due to it can influence the scaffolds' ability of nutrients transmitting, cell seeding and cell reproduction are necessary, therefore, the permeability of the porous structure need to be investigated. Impens et al. found that the permeability will influence the cell seeding efficiency [35]. Ali et al. used finite element analysis to investigate the mechanical properties, permeability and wall shear stress of gyroid and lattice-based rectangular unit cells, the results show that the lattice-based rectangular structure had better mechanical and permeability characteristics than gyroid structure [36]. In this paper, we investigated the permeability of three kinds of gyroid structure through CFD analysis to explore whether this application is suitable for bone scaffold filed.

This paper focusses on the determination of this structure's mechanical behaviour under compression testing (including geometric accuracy and the error of the asprocessed samples), in addition to examining flow characteristics when the structure is used as bone scaffolding. Section 2 introduces the experimental methods, while section 3 presents the results and related discussion. Conclusions and the potential for followup research are discussed in section 4.

\section{Materials and methods}

Compression tests were conducted to study the mechanical properties of $316 \mathrm{~L}$ gyroid structures. The different porosities of the structures achievable by designing different thicknesses, and the relationship between the elastic moduli and porosity, were then obtained from the compression tests. Optical observation was used to determine the potential for error between the designed and produced sizes of the structures; the produced porosity and micromorphology were therefore able to be calculated and observed. To compare the flow ability between different thickness samples, 
computational fluid dynamics (CFD) analysis was used to obtain the pressure drop between inlet and outlet in order to calculate permeability.

\subsection{Powder characteristics}

The samples were built with 316L stainless steel powder, supplied by Renishaw. Fig. 1 (a), which is a scanning electron microscope (SEM) image of $316 \mathrm{~L}$ powder, shows that the powders have a variety of sizes. Fig. 1 (b) shows the appearance of the powder at 3,000X magnification; the powders have smooth surfaces and a spherical structure. The chemical components of 316L stainless steel are shown in table 1.

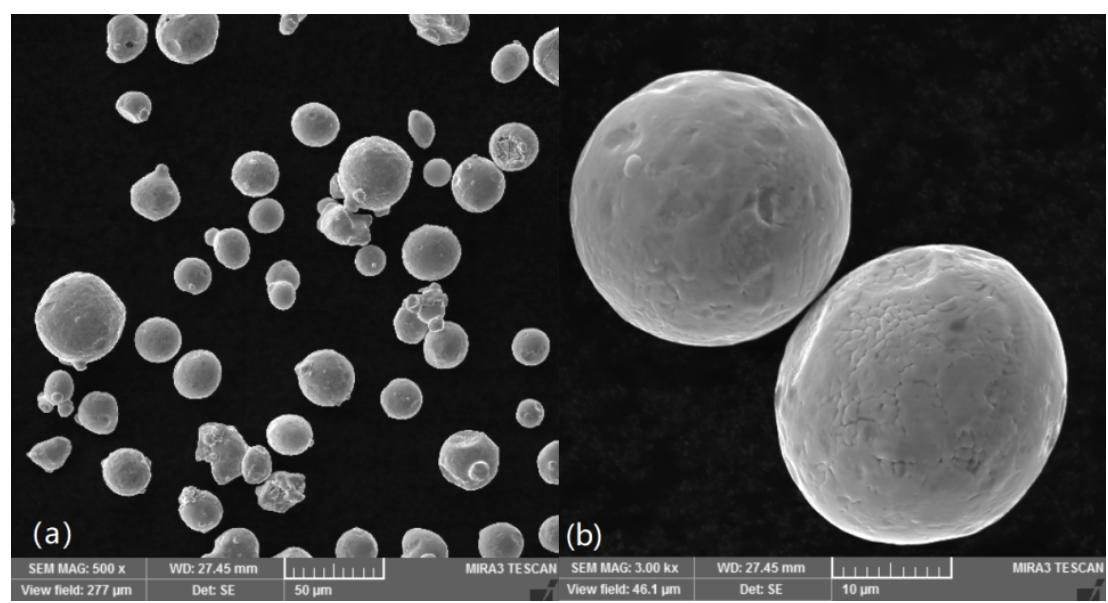

Fig. 1 (a) SEM image of 316L stainless steel powder at 500X magnification; (b) the powder's appearance at 3,000X magnification

Table 1 Powder composition

\begin{tabular}{cccccccccccc}
\hline Element & $\mathrm{Fe}$ & $\mathrm{Cr}$ & $\mathrm{Ni}$ & $\mathrm{Mo}$ & $\mathrm{Mn}$ & $\mathrm{Si}$ & $\mathrm{N}$ & $\mathrm{O}$ & $\mathrm{P}$ & $\mathrm{C}$ & $\mathrm{S}$ \\
\hline Mass & Bal. & 16.00 & 10.00 & 2.00 & $\leq$ & $\leq$ & $\leq$ & $\leq$ & $\leq$ & $\leq$ & $\leq$ \\
$(\%)$ & & to & to & to & 2.00 & 1.00 & 0.10 & 0.10 & 0.045 & 0.03 & 0.03 \\
& & 18.00 & 14.00 & 3.00 & & & & & & & \\
\hline
\end{tabular}

\subsection{Design of the gyroid structures; compression testing}

The gyroid structure is a minimal-surface structure with a characteristic in which the average curvature is zero. This structure has high surface to volume ratio, which can provide large surface area for cell adhesion at a certain volume fraction, and it can found by: 


$$
\sin \frac{2 \pi x}{L} \cos \frac{2 \pi y}{L}+\sin \frac{2 \pi y}{L} \cos \frac{2 \pi z}{L}+\cos \frac{2 \pi x}{L} \sin \frac{2 \pi z}{L}=0
$$

where L decides the length of the cube in which the unit is located. In this study, PTC Creo 3.0 software was used to build 3D models, the unit of the gyroid structure was first built, and the compression and CFD models were modelled by arraying the unit structure. As Fig. 2 (a) shows, all the gyroid structures were built within a cubic space with an edge length (L) of $5 \mathrm{~mm}$ to exclude the size effects [37], and various designs can be constructed with different pore size and porosity. For each sample in the compression test, the number of units in the three orthogonal directions (length $\times$ width $\times$ height) was $4 \times 4 \times 4$. Fig. 2 (b) shows the samples in CFD analysis, due to the repeatability and the symmetry of the scaffold, the number of units in the three orthogonal directions was constructed in $2 \times 2 \times 2$ in order to reduce the simulation time, and it is sufficient to represent the flow field of the whole scaffold [38]. In Fig. 3, $T$ is defined as the thickness of the surface and assigned in the Creo software; $d$ is defined as the pore size, as shown in Eq. (2). Then specifying that $\mathrm{T}$ was equivalent to $0.3,0.4$, and $0.5 \mathrm{~mm}$, we were able to obtain three different gyroid structures, with the pore sizes of each structure set at 2.2, 2.1, and $2.0 \mathrm{~mm}$, named G03, G04, and G05, respectively; and the porosity of each structure set at $80.84 \%, 74.49 \%$, and $68.19 \%$. The CAD models were designed using Creo 3.0 software, and the samples were manufactured using the Renishaw AM250 system and built along the $\mathrm{Z}$ axis.

$$
\mathrm{d}=\frac{L}{2}-T
$$

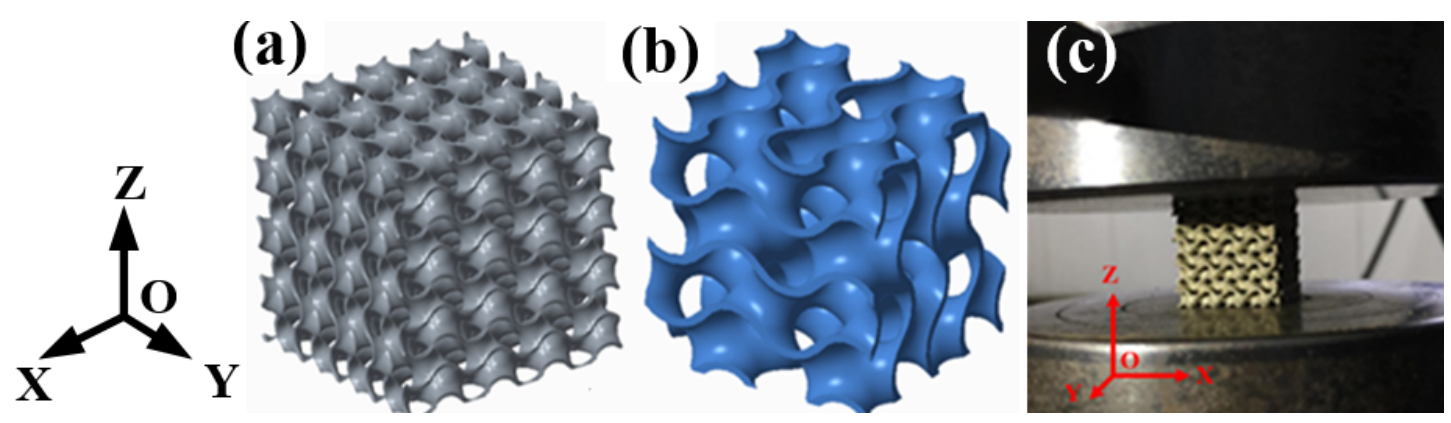

Fig. 2 (a) CAD model of the 316L gyroid structure for compression test $(4 \times 4 \times 4)$; (b) CAD model of gyroid structure for CFD analysis $(2 \times 2 \times 2)$; (c) Compression testing of a $316 \mathrm{~L}$ structure sample 


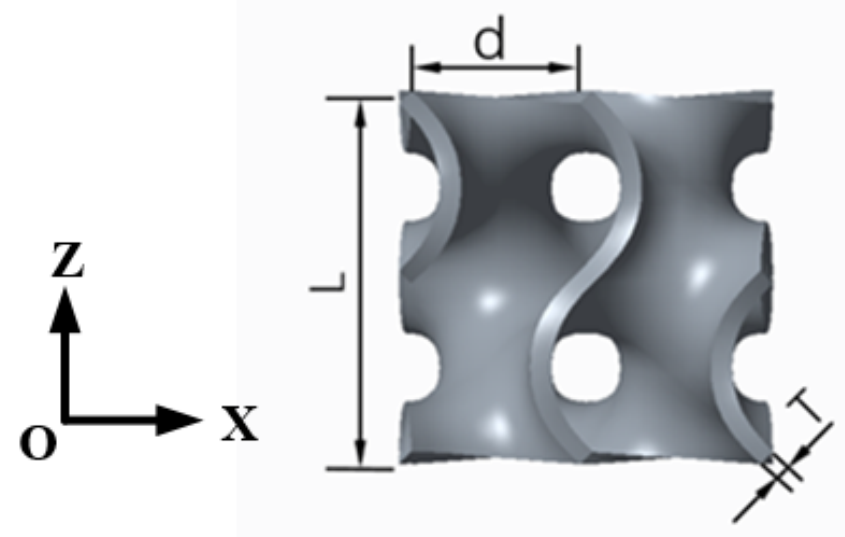

Fig. 3 Unit of the gyroid structure

Fig. 4 shows the three different gyroid structures that were manufactured via SLM. The processing parameters are shown in table 2. Each type of structure was produced three times for the compression testing. All the structures were loaded in the build direction during SLM, which is also called the Z-axis direction. As Fig. 2 (c) shown, all the samples were subjected to static compression without lubricant, and the loading direction is parallel to the build direction. The lateral expansion of all the samples are were free to occur. The displacement rates of the crosshead were set to $3 \mathrm{~mm} / \mathrm{min}$. Nominal stress-strain diagrams were obtainable by recording the displacement and reaction force of the crosshead from each compression test.

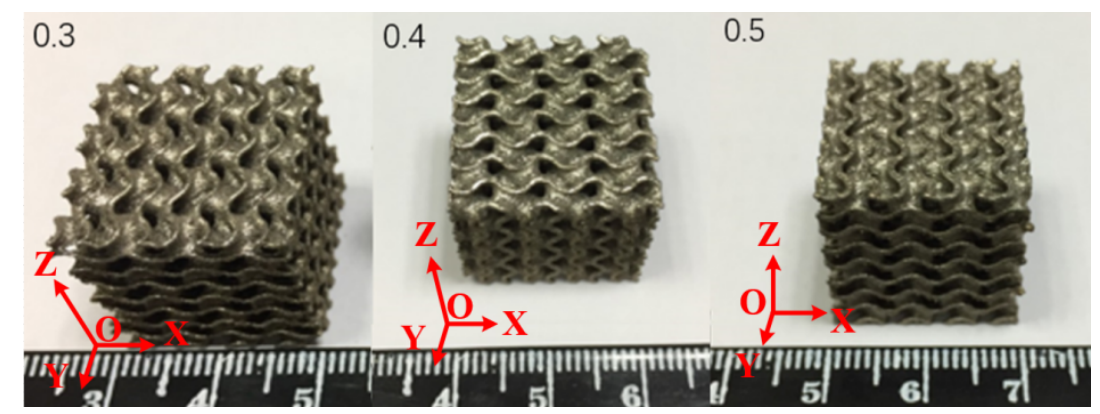

Fig. 4 316L gyroid structure samples manufactured using SLM G03, G04 and G05

Table 2 Manufacturing parameters of the process

\begin{tabular}{ccccc}
\hline $\begin{array}{c}\text { Laser } \\
\text { power }\end{array}$ & $\begin{array}{r}\text { Spot } \\
\text { diameter }\end{array}$ & $\begin{array}{l}\text { Exposure } \\
\text { time }\end{array}$ & $\begin{array}{c}\text { Scan } \\
\text { interval }\end{array}$ & $\begin{array}{c}\text { Layer } \\
\text { thickness }\end{array}$ \\
\hline $180 \mathrm{~W}$ & $70 \mu \mathrm{m}$ & $110 \mathrm{~ms}$ & $65 \mu \mathrm{m}$ & $50 \mu \mathrm{m}$ \\
\hline
\end{tabular}




\subsection{Optical microscopy analysis}

The morphologies of the structures and the possible differences between the designed size and the produced size are important quality indices of products. An optical microscope (VHX-1000 digital microscope) was used to observe the microscopic appearance and the surface thickness of the structures. To obtain reliable data, we randomly selected some areas on the top surface of each sample to measure the thickness at 100X magnification, and one or two point was selected in each area. We measured 5 thickness values of each sample to calculate the average.

\subsection{Micro-CT scanning}

A micro-CT scanner (CD-130BX/ $\mu \mathrm{CT}$, Chongqing Zhence Science and Technology Co., Ltd.) was used to scan the gyroid structures with $0.3 \mathrm{~mm}$ and $0.5 \mathrm{~mm}$ thicknesses, both at $10 \mu \mathrm{m}$ resolution using $150 \mathrm{KV}$ voltage. Fig. 5 shows the placement of G05 and G03 during micro-CT scanning and they were scanned at the same time, the dotted red line represents the boundary between the two samples. 2D slice images were obtained from the scanning process and were then used to analyse any residual powders and the balling phenomenon. Mimics 17.0 software was used to rebuild a 3D model from the 2D slice images; this model was then used to analyse the surface appearance, the manufacturing error, the channel connectivity, and the residual powder inside. ImageJ software was used to measure the thickness of the section with a height of $4,8,12$ and $16 \mathrm{~mm}$ in the direction of height (the build direction), we measured 10 thickness values in the random area of each sample and calculate the average, then investigated the variations in the gyroid thickness inside the structures.

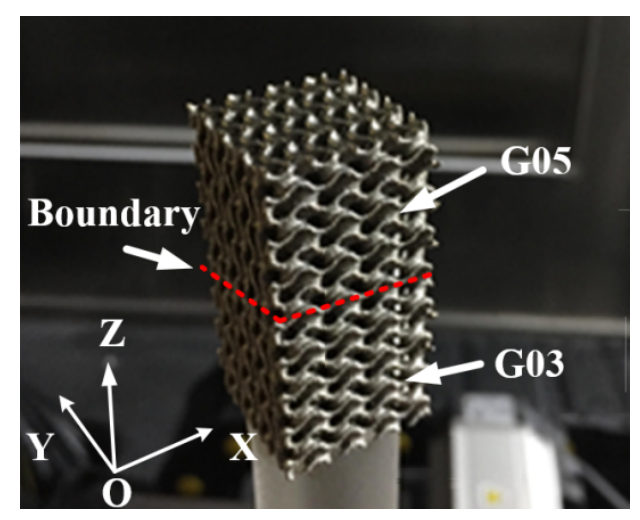

Fig. 5 The placement of G05 (top) and G03 (bottom) during Micro-CT scanning

\subsection{Flow characteristics analysis of CFD}


The mass-transport property is an important indicator for porous structures when they are to be applied in applications such as bone scaffolding. The transport performance of the channel will affect the transfer of nutrients, which is necessary for the growth of bone cells. Considering that the analysed object is incompressible fluid, the Navier-Stokes equation was used in this work.

$$
\begin{gathered}
\rho \frac{\partial v}{\partial \mathrm{t}}=-(\boldsymbol{v} \cdot \nabla) \boldsymbol{v}-\frac{1}{\rho} \nabla P+\mu \nabla^{2} \boldsymbol{v}+\boldsymbol{F} \\
\nabla \cdot \boldsymbol{v}=0
\end{gathered}
$$

Where:

- $\rho$ is the density of the fluid (tonne $/ \mathrm{mm}^{3}$ )

- $\quad \mathrm{v}$ is the velocity of the fluid $(\mathrm{mm} / \mathrm{s})$

- $\mathrm{t}$ is time (s)

- $\nabla$ is the del operator

- $\quad \mathrm{P}$ is pressure $(\mathrm{MPa})$

- $\mu$ is the dynamic viscosity coefficient of the fluid (MPa $\bullet$ s)

- $\quad \mathrm{F}$ is force $(\mathrm{N})$

Water was selected for analysis in this work. The physical properties of water include a density of $1 \mathrm{e}-9$ tonne/mm3 and a viscosity of $1.01 \mathrm{e}-9 \mathrm{MPa} \bullet$. The permeability was used to evaluate the mass-transport ability of different structures using Eq. (5), and the Reynolds number was used to judge the flow type to be either laminar or turbulent, as shown in Eq. (6). The designed pore size d was then used to determine the Reynolds number [33].

$$
\begin{aligned}
\mathrm{K} & =\frac{v \cdot \mu \cdot L}{\Delta P} \\
\mathrm{Re} & =\frac{v \cdot \rho \cdot d}{\mu}
\end{aligned}
$$

Where:

- $\mathrm{K}$ is the permeability coefficient $\left(\mathrm{mm}^{2}\right)$

- $\mathrm{L}$ is the length of the model (mm)

- $\Delta \mathrm{P}$ is the pressure difference $(\mathrm{MPa})$

- $\mathrm{Re}$ is the Reynolds number (-)

- $\mathrm{d}$ is the diameter of the pore $(\mathrm{mm})$

The boundary conditions are shown in Fig. 6, the fluid domains above the scaffold was introduced to avoid the boundary effect. The vertical velocity of water is $1 \mathrm{~mm} / \mathrm{s}$, which was accepted into the inlet for CFD analysis. The pressure of the outlet was zero, 
and the pressure drop $(\Delta \mathrm{P})$ was calculated using Eq. (7), the green area (Plane A) in Fig. 6 was set as the fluid domain at the top of the scaffold. In this condition, the grey area shown in Fig. 6 was set as a symmetric boundary, the blue area was set as a wall boundary, and a no-slip condition was applied on the walls.

$$
\Delta \mathrm{P}=P_{\text {PlaneA }}-P_{\text {outlet }}
$$

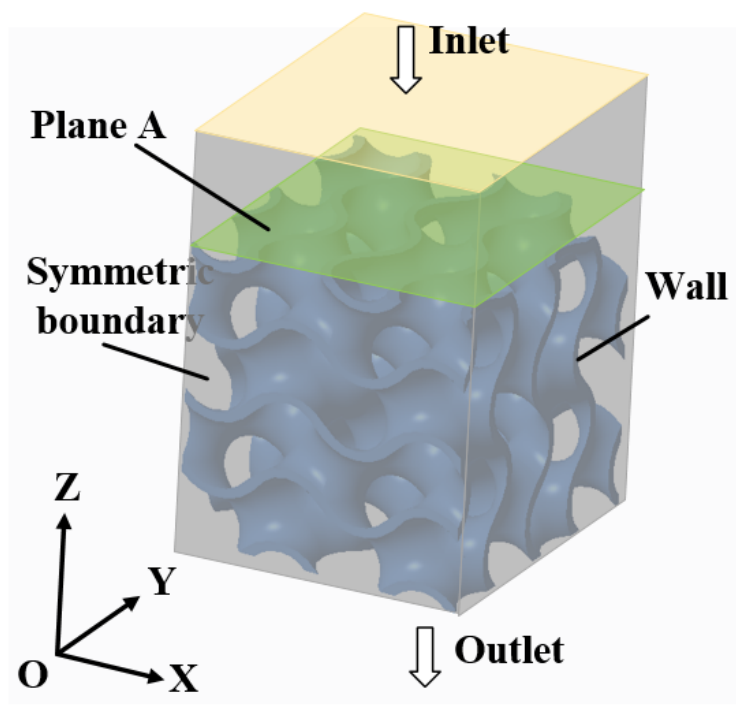

Fig. 6 Boundary conditions in CFD analysis

Abaqus was used in the CFD analysis to emulate the pressure and velocity of the fluids. Table 3 shows the number of elements in each model.

Table 3 Number of elements in the CFD models

\begin{tabular}{lccc}
\hline Thickness (mm) & 0.3 & 0.4 & 0.5 \\
\hline Number of elements & 188,847 & 189,737 & 184,705 \\
\hline
\end{tabular}

\section{Results}

This section presents the mechanical properties of the 316L gyroid using SLM. The elastic moduli and yield stress levels are the main mechanical properties of the 316L gyroid structures examined in this research project. These levels can be determined via compression tests. The relationship between the mechanical properties and the thickness of the gyroid structure produced using SLM could then be observed. The thickness of the surface was measured with an optical microscope at magnifications 
of 200X and more. The shapes of the compressed samples were then viewed through a camera. The manufacturing error was also compared to the designed and manufactured dimensions, and the tendency for this error to vary with changes in thickness was also assessed. The pressure and velocity contours were acquired from the CFD analysis, and the flow characteristics and fluid transport capacity were analysed from these pictures.

\subsection{Mechanical response of the gyroid structures}

Compression tests were used to determine the mechanical properties of the gyroid structures produced using SLM. Fig. 7 shows the nominal stress-strain curves of the three gyroid structures, which were designed with different thicknesses of $0.3,0.4$, and $0.5 \mathrm{~mm}$; and the porosity of each structure set at $80.84 \%, 74.49 \%$, and $68.19 \%$, named G03, G04, and G05, respectively.
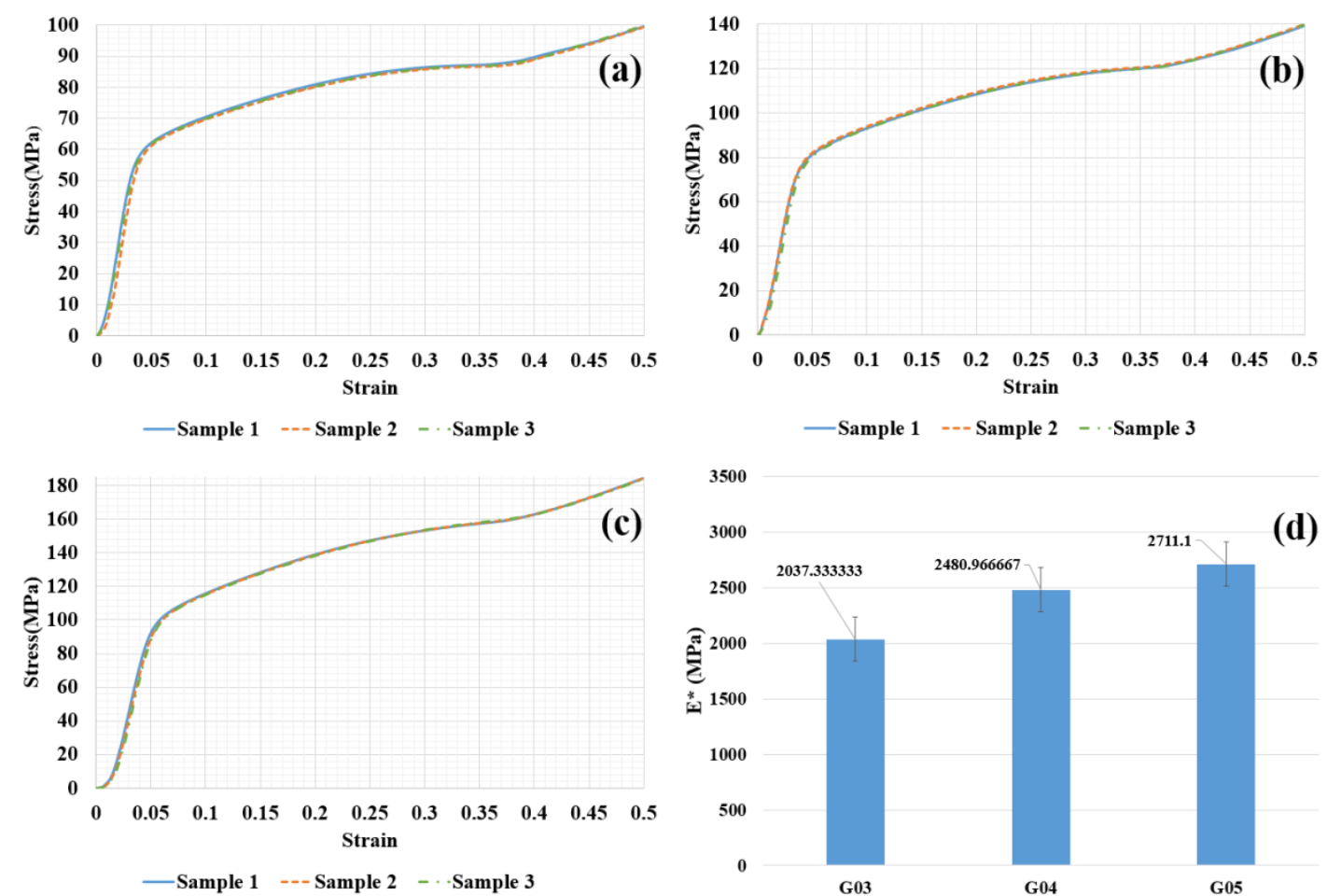

Fig. 7 Nominal stress-strain curves: (a) G03; (b) G04; (c) G05; (d) the elastic moduli of the 316L stainless steel structures.

The stress-strain curves of the gyroid structures of the same thickness were quite similar; all the samples clearly had very similar mechanical properties and performance levels. The SLM process was shown to be capable of maintaining the consistency of the samples. Fig. 8 shows the schematic of elastic modulus and yield strength. It should be noted that a nonlinear stage (oa in Fig. 8) occurred before the linear elastic stage of 
each curve, this happened because the samples and the crosshead established a full contact condition during the compression process [39]. The linear stage ab represents the elastic stage, the slope of $a b$ is defined in terms of the elastic modulus of each structure. The curves also showed that the 316L gyroid structures demonstrated no clear yielding behaviour, so we defined the stress value derived from the $0.2 \%$ residual strain to be the yield strength $\sigma_{\mathrm{y}}$. In Fig. 8 , shifting ab to the right by $0.2 \%$ and intersecting the stress-strain curve ant point $\mathrm{c}$, the stress value derived from point $\mathrm{c}$ to be the yield strength. After point c, the sample was densified and occurred plastic deformation, formed barrel deformation in the centre of the sample and it cannot be restored. The elastic moduli of these three gyroid scaffolds ranged from 2037MPa to $2711 \mathrm{MPa}$ with the porosity ranged from $80.84 \%, 74.49 \%$, and $68.19 \%$. It demonstrated that designing the scaffolds with porous structures is an effective method to reduce the elastic moduli of $316 \mathrm{~L}$ stainless steel. Designing the elastic moduli of scaffold to the appropriate range could avoid the stress shielding between bone and the scaffold. Morgan et al. demonstrated the elastic moduli for trabecular bone in the range of 100 to $4500 \mathrm{MPa}$ $[33,40]$. The elastic moduli of these three structures in this study are within this range.

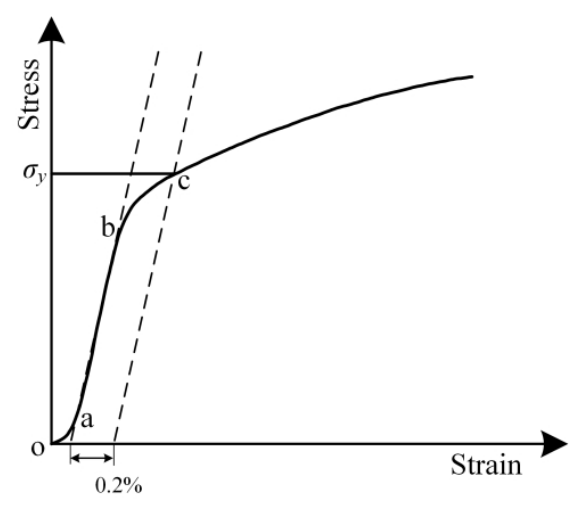

Fig. 8 Schematic of elastic modulus and yield strength

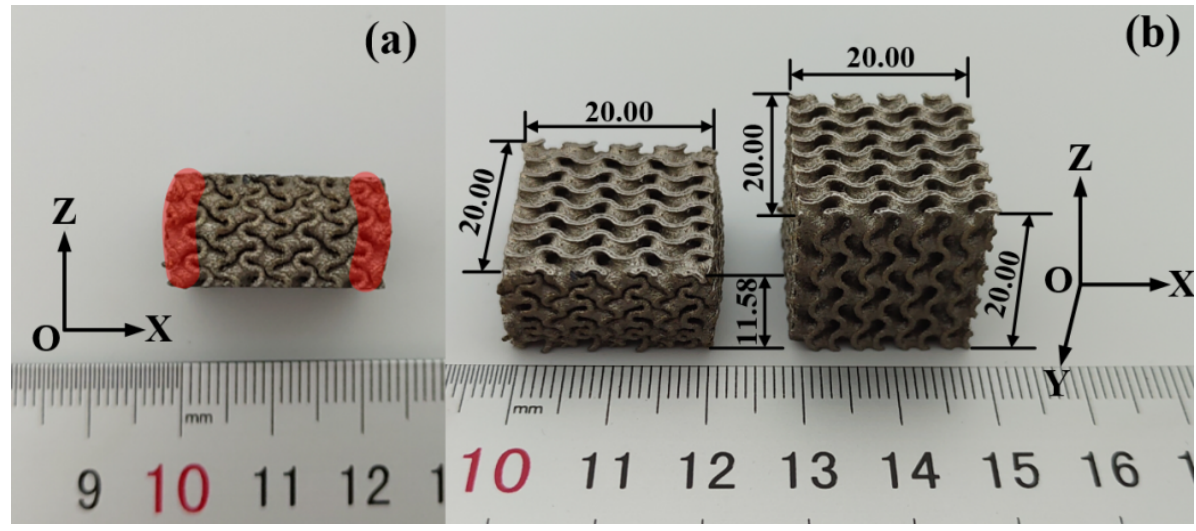

Fig. 9 (a) The sample (G05) after compression testing, (b) comparison of samples after compression and before compression 
Fig. 9 (a) shows the appearance of the G05 structure after compression testing, the sample became barrel-type (as red lines shown) structure under the free lateral expansion condition. Fig. 9 (b) shows the comparison of samples after compression and before compression, the aspect ratio of the sample after compression was about 1:2, and the aspect ratio of the cubic sample was 1:1. The top and the bottom surfaces of the sample was not deformed after compression. It was not broken but was instead compressed along the curves of the gyroid structure. This phenomenon demonstrates that gyroid structure manufactured using SLM exhibit high degrees of toughness and might be used for energy absorption.

Table 4 The elastic moduli and yield strengths of 316L gyroid structures

\begin{tabular}{|c|c|c|c|c|c|c|c|c|}
\hline \multirow{2}{*}{ Size } & \multicolumn{4}{|c|}{ Elastic modulus (MPa) } & \multicolumn{4}{|c|}{ Yield strength $(\mathrm{MPa})$} \\
\hline & $\mathrm{S} 1$ & $\mathrm{~S} 2$ & $\mathrm{~S} 3$ & Average & $\mathrm{S} 1$ & $\mathrm{~S} 2$ & $\mathrm{~S} 3$ & Average \\
\hline \multirow{3}{*}{ G03 } & & & & 2037.3 & & & & $55.0 \pm$ \\
\hline & 2064.1 & 2053.4 & 1994.5 & & 56.1 & 54.0 & 54.9 & \\
\hline & & & & \pm 37.5 & & & & 1.0 \\
\hline \multirow{3}{*}{ G04 } & & & & 2481.0 & & & & $72.1 \pm$ \\
\hline & 2493.2 & 2466.3 & 2483.4 & & 72.1 & 72.6 & 71.6 & \\
\hline & & & & \pm 13.6 & & & & 0.5 \\
\hline \multirow{3}{*}{ G05 } & & & & 2711.1 & & & & $89.4 \pm$ \\
\hline & 2757.8 & 2668.5 & 2707 & & 90.4 & 88.5 & 89.5 & \\
\hline & & & & \pm 44.8 & & & & 1.0 \\
\hline
\end{tabular}

The elastic moduli and yield strengths of the 316L gyroid structures obtained from the compression tests are shown in table 4, where S1, S2, and S3 represent three identical samples. The three samples had the same porosity. As porosity reduced, both the stiffness and yield strength of the gyroid structures increased. For yield strength, these three structures ranged from 55.0 MPa to $89.4 \mathrm{MPa}$ with the porosity of $80.84 \%$, $74.49 \%$, and $68.19 \%$, respectively. The yield strength value of these three structures is higher than the yield strength value of vertebra that ranged from 0.56 to $3.71 \mathrm{MPa}[33$, 41], and higher than the femoral neck's yield strength about 55.3 \pm 8.6 MPa from ref. $[33,40]$. The results show that $316 \mathrm{~L}$ stainless steel bone scaffold consisted of gyroid structure manufactured by SLM can reduce the elastic moduli of the scaffold to the 
same range of elastic moduli of trabecular bone. The yield strength of those structures is higher than the strength of some trabecular bone of the human body. The gyroid structure can match elastic moduli of human bone by change porosity, thus can reduce the chance of stress shielding that may cause the implant failure. The higher mechanical strength of those structures may avoid implant failure under mechanical loading. Thus, SLM-built gyroid structures composed of 316L stainless steel are desirable to design the scaffolds.

\subsection{Micro-morphology of 316 Lyroid structures}

Fig. 10 shows optical microscope images of the gyroid structures produced using SLM with the same cell size of $5 \mathrm{~mm}$ and different designed thicknesses of $0.3,0.4$, and $0.5 \mathrm{~mm}$. As the images show, the gyroid structures were effectively manufactured; the thickness of the as-produced results could also be observed. A small amount of powder was bonded on the surface of the structures, as shown in Fig. 10 (a), (b), and (c), which could have caused the thickness values to be higher than those of the designed size. The surface of the structures was rough; all cells were intact and continuous, which demonstrates that the gyroid structure was effectively self-supported.

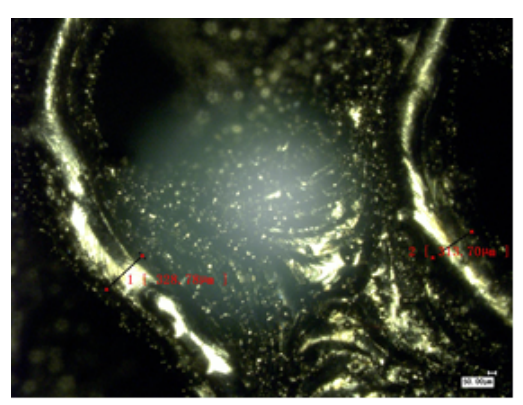

(a) Thickness $=0.3 \mathrm{~mm}$

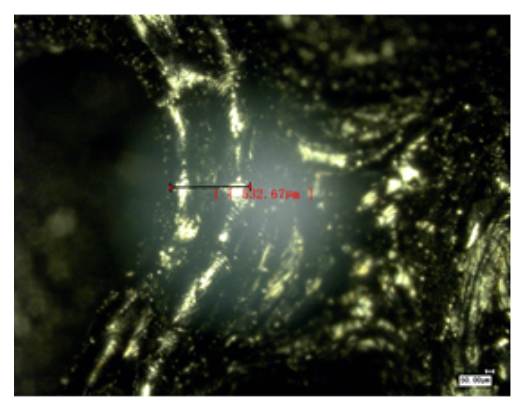

(c) Thickness $=0.5 \mathrm{~mm}$

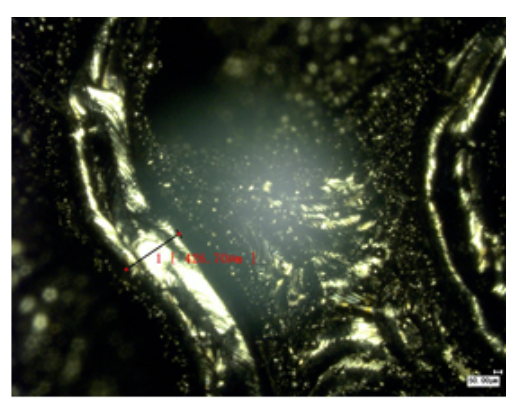

(b) Thickness $=0.4 \mathrm{~mm}$

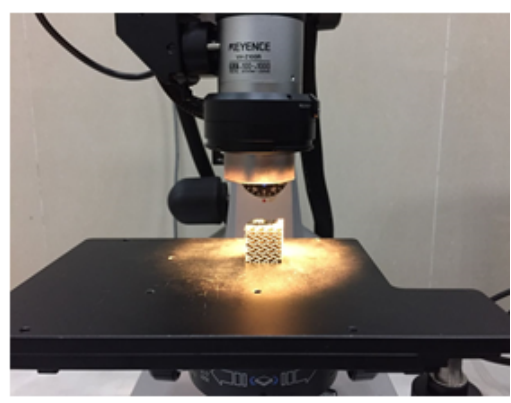

(d) Optical microscope

Fig. 10 Optical microscope images of 316L stainless steel gyroid structures of different thicknesses 
Table 5 The as-produced and designed sizes of the 316L gyroid structures

\begin{tabular}{cccccc}
\hline \multirow{5}{*}{ Size } & \multicolumn{5}{c}{ Thickness $(\mu \mathrm{m})$} \\
\cline { 2 - 6 } & $\mathrm{S} 1$ & $\mathrm{~S} 2$ & $\mathrm{~S} 3$ & Average & Designed \\
\hline G03 & $342.7 \pm 24.3$ & $351.9 \pm 21.6$ & $354.8 \pm 25.4$ & $349.8 \pm 22.7$ & 300 \\
G04 & $431.9 \pm 19.3$ & $437.7 \pm 22.3$ & $430.4 \pm 25.1$ & $433.3 \pm 21.0$ & 400 \\
G05 & $554.4 \pm 27.8$ & $531.5 \pm 5.9$ & $537.6 \pm 20.2$ & $541.2 \pm 21.2$ & 500 \\
\hline
\end{tabular}

Table 5 shows the as-produced sizes (which were measured from the optical microscope images), as well as the designed sizes of the $316 \mathrm{~L}$ gyroid structure unit at the same size of $5 \mathrm{~mm}$. As the table shows, the as-produced thickness levels were higher than the designed thickness levels; the as-produced thickness levels were found to be $349.8,433.3$, and $541.2 \mu \mathrm{m}$, against the designed thickness levels of 300, 400, and 500 $\mu \mathrm{m}$, respectively. The range of error was approximately 40 to $50 \mu \mathrm{m}$, and no obvious correlation was found between the error and the designed thickness. Fig. 11 shows the range of error between the as-produced and designed sizes of three different thicknesses; each sample was measured five times, and the averages were calculated. Our observations determined that the significance of the error would not increase as design thickness increased. Fig. 12 shows the variations in the gyroid thickness in the height direction. The thickness of G03 in the range of 40 to $60 \mu \mathrm{m}$, and the thickness of G03 in the range of 55 to $70 \mu \mathrm{m}$. The results show that there is no definite relationship between the thickness error and the height of samples. By comparing the thickness error of the top surface and the inside of G03 and G05, it shows that the thickness error has a good consistency for G03, the thickness in the similar range of 40 to $60 \mu \mathrm{m}$. The values of thickness error of the inside G05 are little larger than the top surface, however, considering of the $10 \mu \mathrm{m}$ resolution, the difference of 10 to $20 \mu \mathrm{m}$ is acceptable, and the manufacturing error inside the G05 has a good consistency. In general, gyroid structures fabricated by SLM can ensure stability. 


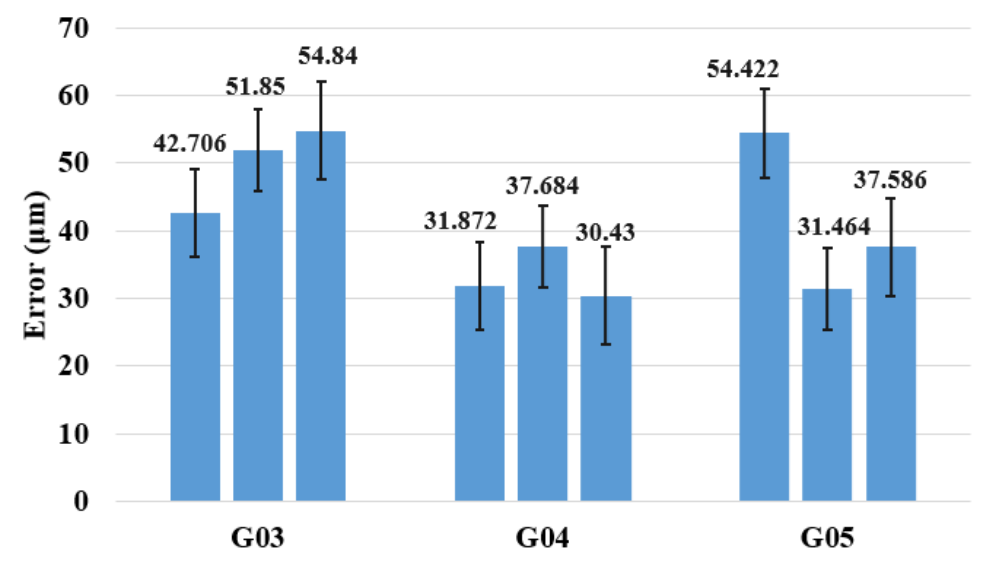

Fig. 11 Error between as-produced sizes and designed sizes of three different porosity (the top surface)

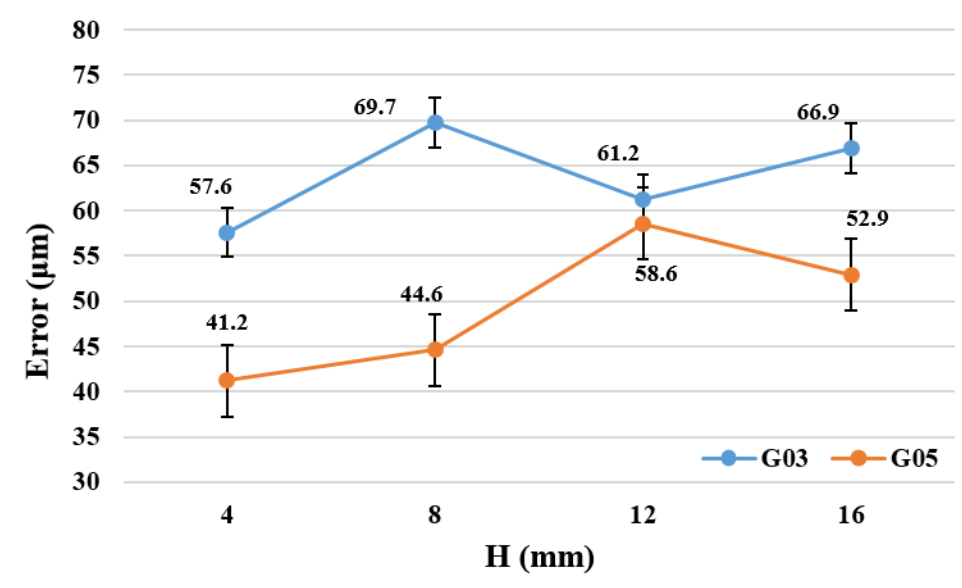

Fig. 12 Error between as-produced sizes and designed sizes variations of G03 and G05 in the samples height $(\mathrm{H})$ direction (from the 2D slice images)

The 2D images obtained from CT scanning showed the residual powders and balling phenomenon of the samples. A micro-CT scanner was used to slice the samples into 1,600 layers, such that each layer's thickness was around $0.0125 \mathrm{~mm}$. As Fig. 13 (a) shows, the 3D models of G03 and G05 were rebuilt using Mimics software. Fig. 13 (b) and (c) show the surface of G03, where the surface is rough, and residual powder remains on the outside surface. Fig. 13 (d) and (e) show the outside surface of G05, the pores are not plugged. Balling phenomenon and residual powders were then analysed using the 2D images. Fig. 14 (a) and (b) show the slice images of G03 in the direction of processing; no powder remains, and all the pores are coherent, and no broken surface was found. Fig. 14 (c) and (d) show the 2D slice images of G05; some powder remains on the top of the processing direction, and most of the pores are clogged by the powder, but no powder was found on the remaining slice planes. 


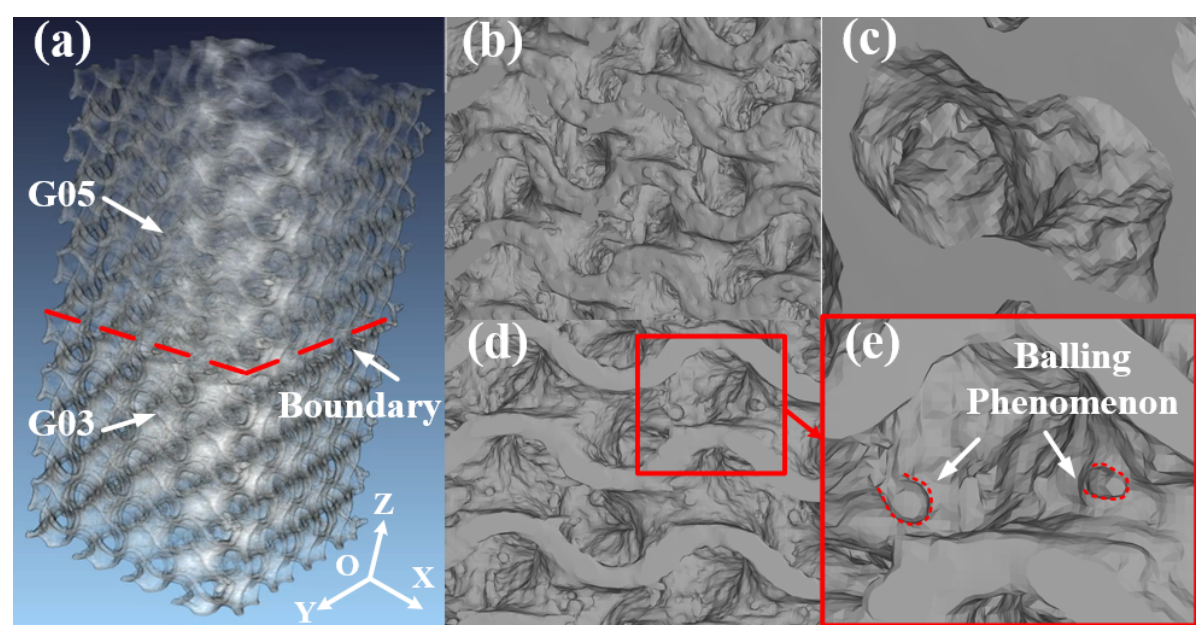

Fig. 13 (a) Re-built models of G05 (top) and G03 (bottom); (b) and (c) surface of G03; (d) and (e) surface of G05 (the dotted red lines represent the balling phenomenon)

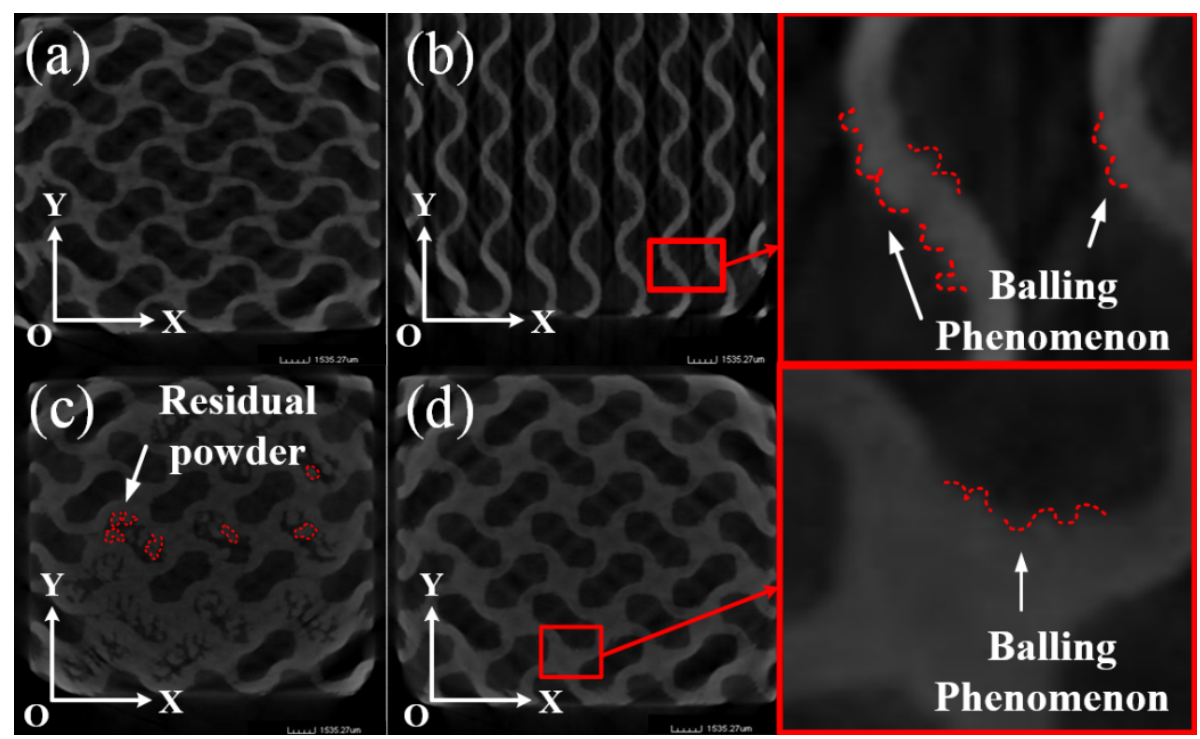

Fig. 14 Micro-CT 2D images: (a) and (b) G03 (the dotted red lines represent the balling phenomenon); (c) and (d) G05 (the dotted red lines represent the residual powder and balling phenomenon, respectively)

\subsection{Flow characteristics of gyroid structure scaffolding}

In order to investigate the characteristics of gyroid structure scaffolding of the same physical dimensions with different thicknesses, the pressure and velocity distributions were used to analyse the discrepancy. The pressure drop and the permeability were used to quantify the transport performance among different structures. As Fig. 15 shows, the pressure decreased from the inlet to the outlet in all structures, and structures with different thicknesses were found to have approximately similar pressure distributions. The velocity distribution was irregular except in the 
vertical direction because of the scaffold's complex spatial structure. As Fig. 15 (b), (d), and (f) show, from the velocity contours, the velocity values of the centre of the side surface were much larger than the values of the surrounding area of the centre and inlet area. This phenomenon showed that the gyroid structure was capable of accelerating the fluid due to the curved structures [36], this accelerated behaviour could be beneficial to the transport of nutrients and the cell migration to the deepest part of the scaffold.

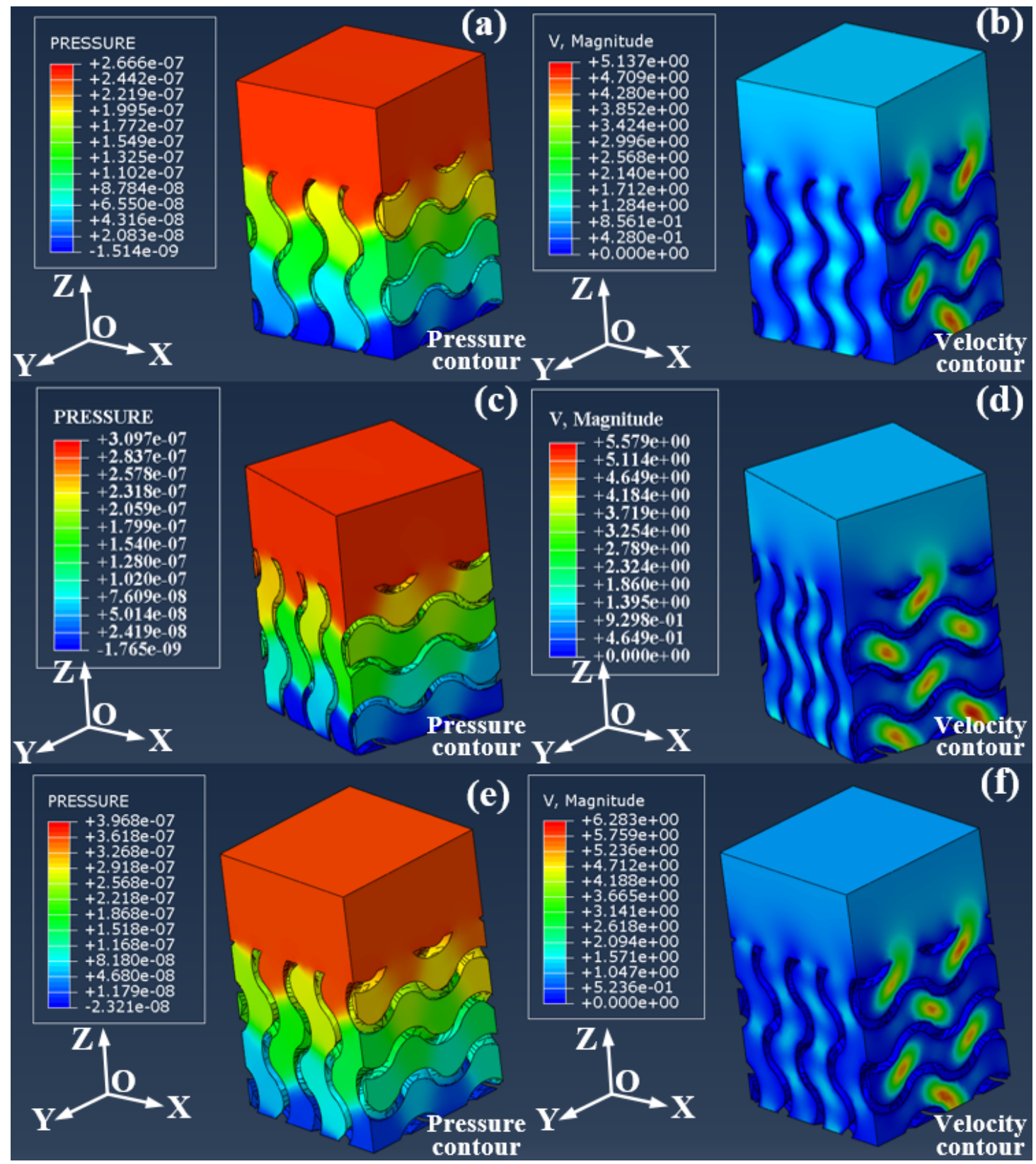

Fig. 15 Pressure (MPa) and velocity $(\mathrm{mm} / \mathrm{s})$ contours of gyroid structures with an inlet velocity of $1 \mathrm{~mm} / \mathrm{s}$; (a) pressure contour of G03; (b) velocity contour of G03; (c) pressure contour of G04; (d) velocity contour of G04; (e) pressure contour of G05; (f) velocity contour of G05 
A diagram of the distribution of streamline and velocity vectors of G05 is shown in Fig. 16. From the distribution of the streamline vector, almost no turbulence occurred in the channel, and the water flowed smoothly from the inlet to the outlet. From the distribution of the velocity vector, the velocity values in the centre of the channel were clearly larger than those in the surrounding area. Higher velocity of the centre area could transport the nutrients, oxygen etc. into deeper end of scaffold, and this promoted cell migration; Lower velocity of the surrounding area due to the frictional effects that impede fluid flows [33, 42]; However, lower velocity and higher surface friction increased the chances of cell's attachment to the surface because it allowed cells have more time to attach to the scaffold's surface [43]. The velocity of the fluid in the scaffold is important for the cells, both for the transport of mass and cell attachment. It was closely related to permeability, therefore the permeability with proper values should be designed.

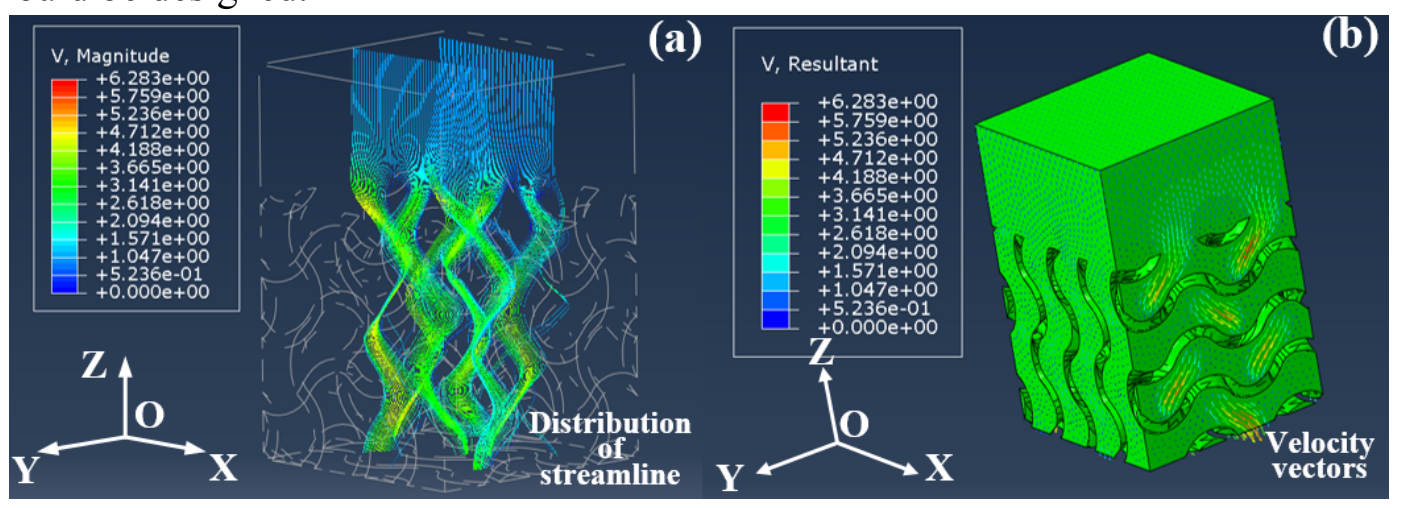

Fig. 16 (a) Distribution of streamline of G05 (mm/s); (b) velocity vectors of G05 (mm/s)

To compare the mass-transport properties among different models, the pressure drop $(\triangle P)$ and the permeability $(K)$ values of each model were calculated using Eq. (7) and (5). Fig. 17 shows the $\triangle \mathrm{P}$ of the three scaffold models; the pressure drop increased as the pore diameter decreased, which has good agreement with the results of Ali D [36]. The figure shows that a small pore diameter causes a higher pressure drop, which results in higher velocity. Permeability is a key parameter for both mass-transport and cell seeding efficiency, the permeability should be designed in the suitable range to the human cancellous bones, and hence the prediction of the permeability of porous scaffolds is essential at the design stage. As Fig. 18 shows, the permeability is reduced with decreases to the scaffold's pore size, which shows that a larger pore diameter contributes to permeability. In general, a larger pore diameter reduces the pressure drop (which is positively related to transport speed), and a larger pore diameter increases the 
permeability of the scaffolding. Pore diameter is hence a key factor that needs to be taken into account. As Table 6 shows, the permeability of this study ranges from 27.4 $\times 10^{-9} \mathrm{~m}^{2}$ to $40.3 \times 10^{-9} \mathrm{~m}^{2}$, the values are in the range of the results provided by the previous studies on metallic porous scaffolds [36, 43, 44]. They are slightly larger than that of some human cancellous bones $[45,46]$, however, they are of the same order of magnitude, and the span of the permeability of human bones is large. It indicates that we could design metallic porous scaffolds that have the similar permeability to human cancellous bones by changing the porosity and pore size of porous structures, and the SLM-built gyroid scaffolds composed of 316L stainless steel are suitable as bone implants.

Table 6 Permeability of bone and porous scaffolds composed of biomaterials

\begin{tabular}{|c|c|c|c|c|c|c|}
\hline & $\begin{array}{l}\text { Beaudoin, A } \\
\quad \mathrm{J} \text { et al. }\end{array}$ & $\begin{array}{l}\text { S. } \\
\text { Gómez } \\
\text { et al. }\end{array}$ & $\begin{array}{c}\text { S. Van } \\
\text { Bael et al. }\end{array}$ & $\begin{array}{c}\text { Davar } \\
\text { Ali et al. }\end{array}$ & $\begin{array}{c}\text { E. A. } \\
\text { NAUMAN } \\
\text { et al. }\end{array}$ & $\begin{array}{c}\text { Current } \\
\text { work }\end{array}$ \\
\hline Permeabilit & $0.467 \sim 14.800$ & $5.0 \sim 45.0$ & $5.06 \sim 30.50$ & $1.0 \sim 36.0$ & $0.0268 \sim 20.0$ & $27.4 \sim 40.3$ \\
\hline $\mathrm{y}\left(\times 10^{-9} \mathrm{~m}^{2}\right)$ & a $[45]$ & $\mathrm{b}$ [44] & $\mathrm{b}[43]$ & b [36] & a $[46]$ & $\mathrm{b}$ \\
\hline \multicolumn{7}{|l|}{ a bone } \\
\hline${ }^{\mathrm{b}}$ porous scaff & & & & & & \\
\hline
\end{tabular}

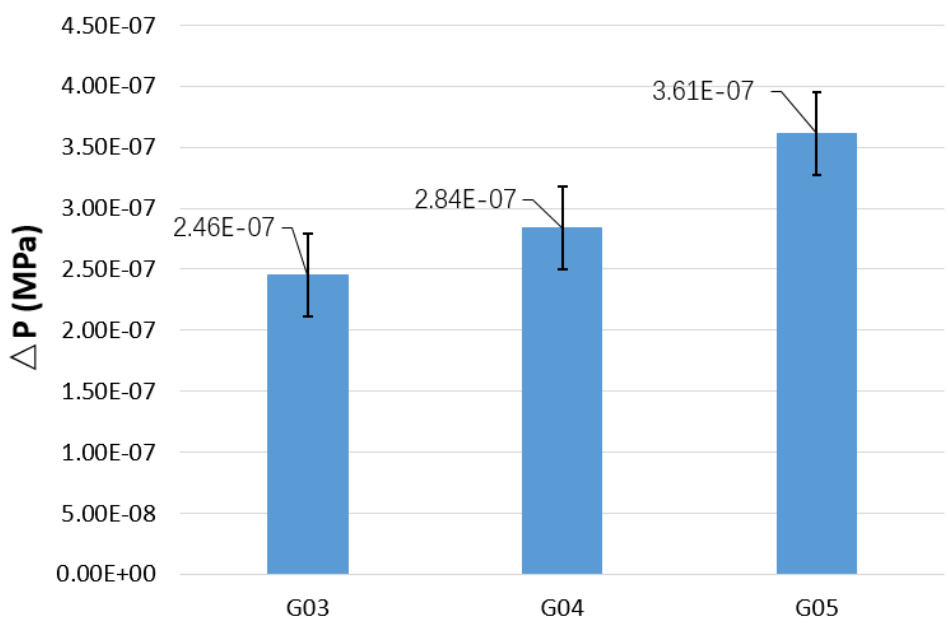

Fig. 17 Measured $\triangle \mathrm{P}$ in gyroid structure scaffolding 


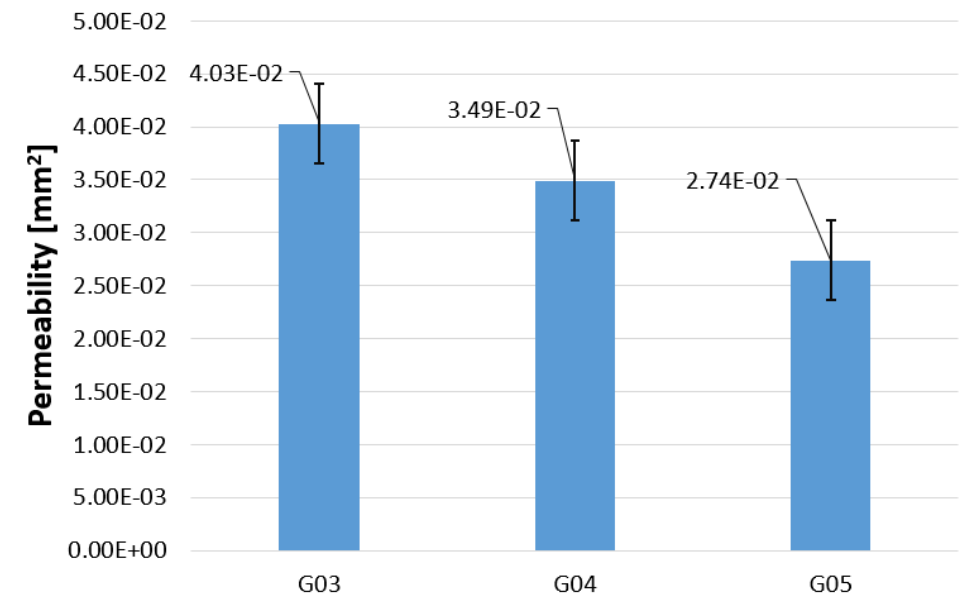

Fig. 18 Permeability of gyroid structure scaffolding

\section{Conclusion}

In this study, three $316 \mathrm{~L}$ stainless steel gyroid structures with $0.3,0.4$, and $0.5 \mathrm{~mm}$ thicknesses (the porosity of each structure set at $80.84 \%, 74.49 \%$, and $68.19 \%$ ) were modelled and fabricated via selective laser melting (SLM). The powder characteristic of 316L powder was observed, and the mechanical properties of different samples were calculated by the strain-stress curves obtained from the compression tests. The qualitative relationships between various mechanical properties and porosity were also determined. An optical microscope and a micro-CT scanner were used to research the surface characteristics, residual powders and the balling phenomenon of the samples. The mass-transport properties of the three models were investigated through their computational fluid dynamics (CFD) values. The results of this study proved that $316 \mathrm{~L}$ gyroid structures were suitable to be designed as bone scaffolds in terms of mechanical properties and mass-transport properties, and had significant promise for applying as bone scaffolds. We may draw the following conclusions:

First, the elastic moduli of the structures with different porosity of G03, G04, and G05 were found to be 2037.3, 2481.0, and 2711.1 MPa, respectively. The values were in the range of the elastic moduli of trabecular bones. Moreover, the yield strengths were 55.0, 72.1, and 89.4 MPa, respectively. They were higher than the values of some cancellous bones, the higher yield strength could avoid implant failure under mechanical loading. The 316L gyroid structures did not fracture after the compression tests, which demonstrates high degrees of toughness. In terms of mechanical properties, the results of this study proved the possibility of using gyroid structures to design bone 
scaffolds. By changing the porosity and pore size of the gyroid structures, we could get the bone scaffolds with the similar elastic moduli and yield strength to human bones, to avoid the stress shielding and implant failure.

Second, the gyroid structure was self-supported, and the surface was rough. The residual powders and balling phenomenon of the exterior and internal surfaces were both analysed through micro-CT scanning, and the balling phenomenon was observed on all surfaces. Residual powder blocking the channel was only observable on the top plane of G05. The as-produced thickness was about $40 \mu \mathrm{m}$ thicker than that of the designed sizes. The error between the designed and as-produced sizes was not indicative of any obvious relationship with thickness. The manufacturing error of the top surface and the inside of G03 and G05 has good consistency, it has no obvious relationship with the height, and they all show that SLM can ensure the stability of manufacturing.

Finally, in terms of mass-transport properties, it shows that the gyroid structures had the potential of being designed as bone scaffolds. According to the CFD analysis, the fluid showed good flow performance in the scaffold, with almost no turbulence. The scaffold with a larger pore diameter was also found to have higher permeability than scaffolding with smaller-diameter pores. The values of the permeability of the scaffolds in this study ranged from $27.4 \times 10^{-9} \mathrm{~m}^{2}$ to $40.3 \times 10^{-9} \mathrm{~m}^{2}$, the values were in the range of the previous studies on metallic porous scaffolds, and they were of the same order of magnitude with the human cancellous bones. We could predict the permeability of the scaffold at the design stage to ensure that it was similar to the original bone, to get good mass-transport properties and cell seeding efficiency.

For future work, the mechanical properties of structures should be predicted via finite element analysis (FEA) before design work commences. Cell culture experimentation will also be required, in which cell adsorption and growth will be observed in order to analyse the biocompatibility of $316 \mathrm{~L}$ gyroid structures and the effects of permeability on cell seeding efficiency. At the same time, a test-bed should be built to do the permeability test.

Acknowledgements This study was supported by the Natural Science Foundation of China (Grant No: 51575069) and Graduate Research and Innovation Foundation of Chongqing, China (Grant No. CYB18024). 


\section{References:}

[1] A. Ajdari, B.H. Jahromi, J. Papadopoulos, H. Nayeb-Hashemi, A. Vaziri, Hierarchical honeycombs with tailorable properties, Int J Solids Struct 49 (2012) 1413-1419.

[2] M.R. Karamooz Ravari, M. Kadkhodaei, M. Badrossamay, R. Rezaei, Numerical investigation on mechanical properties of cellular lattice structures fabricated by fused deposition modeling, Int $\mathbf{J}$ Mech Sci 88 (2014) 154-161.

[3] O.E. Sotomayor, H.V. Tippur, Role of cell regularity and relative density on elastoplastic compression response of 3-D open-cell foam core sandwich structure generated using Voronoi diagrams, Acta Mater 78 (2014) 301-313.

[4] I. Maskery, N.T. Aboulkhair, A.O. Aremu, C.J. Tuck, I.A. Ashcroft, Compressive failure modes and energy absorption in additively manufactured double gyroid lattices, Additive Manufacturing 16 (2017) 24-29.

[5] C. Emmelmann, M. Petersen, J. Kranz, E. Wycisk, Bionic Lightweight Design by Laser Additive Manufacturing (LAM) for Aircraft Industry, 8065 (2011).

[6] G.E. Ryan, A.S. Pandit, D.P. Apatsidis, Porous titanium scaffolds fabricated using a rapid prototyping and powder metallurgy technique, Biomaterials 29 (2008) 3625-3635.

[7] Q. Han, R. Setchi, S.L. Evans, Characterisation and milling time optimisation of nanocrystalline aluminium powder for selective laser melting, The International Journal of Advanced Manufacturing Technology 88 (2017) 1429-1438.

[8] N. Read, W. Wang, K. Essa, M.M. Attallah, Selective laser melting of AlSi10Mg alloy: Process optimisation and mechanical properties development, Mater Design 65 (2015) 417-424.

[9] L. Zeng, N. Xiang, B. Wei, A comparison of corrosion resistance of cobalt-chromium-molybdenum metal ceramic alloy fabricated with selective laser melting and traditional processing., J Prosthet Dent 112 (2014) 1217-1224.

[10] X.Y. Cheng, S.J. Li, L.E. Murr, Z.B. Zhang, Y.L. Hao, R. Yang, F. Medina, R.B. Wicker, Compression deformation behavior of Ti-6A1-4V alloy with cellular structures fabricated by electron beam melting, J Mech Behav Biomed 16 (2012) 153-162.

[11] M. Ma, Z. Wang, M. Gao, X. Zeng, Layer thickness dependence of performance in high-power selective laser melting of 1Cr18Ni9Ti stainless steel, J Mater Process Tech 215 (2015) 142-150.

[12] M. Akita, Y. Uematsu, T. Kakiuchi, M. Nakajima, R. Kawaguchi, Defect-dominated fatigue behavior in type 630 stainless steel fabricated by selective laser melting, Materials Science \& Engineering A 666 (2016) 19-26.

[13] P. Dickens, M. Khan, Selective laser melting (SLM) of pure gold for manufacturing dental crowns, Rapid Prototyping J 20 (2014) 1.

[14] J. Wang, A.G. Evans, K. Dharmasena, H.N.G. Wadley, On the performance of truss panels with Kagomé cores, Int J Solids Struct 40 (2003) 6981-6988.

[15] V.S. Deshpande, N.A. Fleck, M.F. Ashby, Effective properties of the octet-truss lattice material, J Mech Phys Solids 49 (2001) 1747-1769.

[16] J.C. Wallach, L.J. Gibson, Mechanical behavior of a three-dimensional truss material, Int J Solids Struct 38 (2001) 7181-7196.

[17] S.V. Bael, G. Kerckhofs, M. Moesen, G. Pyka, J. Schrooten, Micro-CT-based improvement of geometrical and mechanical controllability of selective laser melted Ti6Al4V porous structures. 
[18] S.S.S.S. McKown, Y.S.S. Shen, W.K.S.S. Brookes, C.J.S.S. Sutcliffe, W.J.S.S. Cantwell, G.S.S.S. Langdon, G.N.S.S. Nurick, M.D.S.S. Theobald, The quasi-static and blast loading response of lattice structures., Int J Impact Eng (2008) 795-810.

[19] Q. Feng, Q. Tang, Y. Liu, R. Setchi, S. Soe, S. Ma, L. Bai, Quasi-static analysis of mechanical properties of Ti6Al4V lattice structures manufactured using selective laser melting, Int J Adv Manuf Tech (2017) 1-13.

[20] M. Fantini, M. Curto, F. De Crescenzio, in: B. Eynard, V. Nigrelli, S.M. Oliveri, G. Peris-Fajarnes, S. Rizzuti (Eds), Advances on Mechanics, Design Engineering and Manufacturing : Proceedings of the International Joint Conference on Mechanics, Design Engineering \& Advanced Manufacturing (JCM 2016), 14-16 September, 2016, Catania, Italy, Springer International Publishing, Cham, 2017, pp. 425-435.

[21] C. Yan, L. Hao, A. Hussein, P. Young, D. Raymont, Advanced lightweight 316L stainless steel cellular lattice structures fabricated via selective laser melting, Materials and Design (2014) 533541.

[22] A.L. Olivares, E. Marshal, J.A. Planell, D. Lacroix, Finite element study of scaffold architecture design and culture conditions for tissue engineering, Biomaterials 30 (2009) 6142-6149.

[23] G.S. Jung, M.J. Buehler, Multiscale Mechanics of Triply Periodic Minimal Surfaces of ThreeDimensional Graphene Foams, Nano Lett 18 (2018) 4845-4853.

[24] Z. Qin, G.S. Jung, M.J. Kang, M.J. Buehler, The mechanics and design of a lightweight threedimensional graphene assembly, Science advances 3 (2017) e1601536.

[25] F.P.W. Melchels, J. Feijen, D.W. Grijpma, A poly(D,L-lactide) resin for the preparation of tissue engineering scaffolds by stereolithography, Biomaterials 30 (2009) 3801-3809.

[26] I. Ullah, J. Elambasseril, M. Brandt, S. Feih, Performance of bio-inspired Kagome truss core structures under compression and shear loading, Compos Struct 118 (2014) 294-302.

[27] P.H. Warnke, T. Douglas, P. Wollny, E. Sherry, M. Steiner, S. Galonska, S.T. Becker, I.N. Springer, J. Wiltfang, S. Sivananthan, Rapid prototyping: porous titanium alloy scaffolds produced by selective laser melting for bone tissue engineering, Tissue Eng Part C Methods 15 (2009) 115-124.

[28] E. Butev, Z. Esen, S. Bor, Characterization of Ti6Al7Nb alloy foams surface treated in aqueous $\mathrm{NaOH}$ and $\mathrm{CaCl} 2$ solutions, J Mech Behav Biomed Mater 60 (2016) 127-138.

[29] J. Kadkhodapour, H. Montazerian, A.C. Darabi, A.P. Anaraki, S.M. Ahmadi, A.A. Zadpoor, S. Schmauder, Failure mechanisms of additively manufactured porous biomaterials: Effects of porosity and type of unit cell, J Mech Behav Biomed 50 (2015) 180-191.

[30] S.J. Hollister, Porous scaffold design for tissue engineering, Nat Mater 4 (2005) 518-524.

[31] S.H. Cartmell, B.D. Porter, A.J. Garcia, R.E. Guldberg, Effects of medium perfusion rate on cellseeded three-dimensional bone constructs in vitro, Tissue Eng 9 (2003) 1197-1203.

[32] M.E. Gomes, V.I. Sikavitsas, E. Behravesh, R.L. Reis, A.G. Mikos, Effect of flow perfusion on the osteogenic differentiation of bone marrow stromal cells cultured on starch-based three-dimensional scaffolds, J Biomed Mater Res a 67 (2003) 87-95.

[33] F.S.L. Bobbert, K. Lietaert, A.A. Eftekhari, B. Pouran, S.M. Ahmadi, H. Weinans, A.A. Zadpoor, Additively manufactured metallic porous biomaterials based on minimal surfaces: A unique combination of topological, mechanical, and mass transport properties, Acta Biomater 53 (2017) $572-584$

[34] M. Speirs, B. Van Hooreweder, J. Van Humbeeck, J.P. Kruth, Fatigue behaviour of NiTi shape memory alloy scaffolds produced by SLM, a unit cell design comparison, J Mech Behav Biomed 
70 (2017) 53-59.

[35] S. Impens, Y. Chen, S. Mullens, F. Luyten, J. Schrooten, Controlled Cell-Seeding Methodologies: A First Step Toward Clinically Relevant Bone Tissue Engineering Strategies, Tissue Engineering Part C: Methods 16 (2010) 1575-1583.

[36] D. Ali, S. Sen, Finite element analysis of mechanical behavior, permeability and fluid induced wall shear stress of high porosity scaffolds with gyroid and lattice-based architectures, J Mech Behav Biomed 75 (2017) 262-270.

[37] H. Montazerian, E. Davoodi, M. Asadi-Eydivand, J. Kadkhodapour, M. Solati-Hashjin, Porous scaffold internal architecture design based on minimal surfaces: A compromise between permeability and elastic properties, Mater Design 126 (2017) 98-114.

[38] S. Truscello, G. Kerckhofs, S. Van Bael, G. Pyka, J. Schrooten, H. Van Oosterwyck, Prediction of permeability of regular scaffolds for skeletal tissue engineering: A combined computational and experimental study, Acta Biomater 8 (2012) 1648-1658.

[39] Q. Feng, Q. Tang, S. Soe, Y. Liu, R. Setchi, An Investigation into the Quasi-Static Response of Ti6A14V Lattice Structures Manufactured Using Selective Laser Melting. in: R. Setchi, R.J. Howlett, Y. Liu, P. Theobald (Eds), Springer International Publishing, Cham, 2016, pp. 399-409.

[40] E.F. Morgan, H.H. Bayraktar, T.M. Keaveny, Trabecular bone modulus-density relationships depend on anatomic site, J Biomech 36 (2003) 897-904.

[41] D.L. Kopperdahl, T.M. Keaveny, Yield strain behavior of trabecular bone, J Biomech 31 (1998) 601-608.

[42] F.J. O'Brien, B.A. Harley, M.A. Waller, I.V. Yannas, L.J. Gibson, P.J. Prendergast, The effect of pore size on permeability and cell attachment in collagen scaffolds for tissue engineering., Technology and health care : official journal of the European Society for Engineering and Medicine 15 (2007) 3-17.

[43] S. Van Bael, Y.C. Chai, S. Truscello, M. Moesen, G. Kerckhofs, H. Van Oosterwyck, I.P. Kruth, J. Schrooten, The effect of pore geometry on the in vitro biological behavior of human periosteumderived cells seeded on selective laser-melted Ti6A14V bone scaffolds, Acta Biomater 8 (2012) 2824-2834.

[44] S. Gomez, M.D. Vlad, J. Lopez, E. Fernandez, Design and properties of 3D scaffolds for bone tissue engineering, Acta Biomater 42 (2016) 341-350.

[45] A.J. Beaudoin, W.M. Mihalko, W.R. Krause, Finite element modelling of polymethylmethacrylate flow through cancellous bone, J Biomech 24 (1991) 127.

[46] E.A. Nauman, K.E. Fong, T.M. Keaveny, Dependence of Intertrabecular Permeability on Flow Direction and Anatomic Site, Ann Biomed Eng 27 (1999) 517-524. 